\section{A bigger can of worms?}

SIR-Maddox', commenting on a review by Joseph and Preziosi ${ }^{2}$, suggested that there are reasons why Fourier's law should be regarded "as the crudest approximation to the truth". The assertion that a fundamental law is, or could be, flawed would be expected to lead to a heated debate; the absence of a response in the year since the articles were published suggests that whatever was troublesome was either so trivial that it has gone away, or so profound as to deter anyone from grasping the nettle. We have considered the problem of heat conductance and some of the wider theoretical implications, particularly as they affect biologists' thinking about 'diffusion'.

Although Maddox points out that "mathematically, Fourier's law ... is strictly equivalent to the diffusion equation", Fourier's work on the problem of heat (energy) movement in metals ${ }^{3}$ antedates by many years Fick's theory of diffusion. Fick transposed Fourier's idea to the movement of solutes in liquids ${ }^{+}$without apparently providing experimental evidence to justify this extrapolation.

Fick's law subsequently seems to have been elevated to the level of orthodoxy: more recent attempts to validate it have not been successful. As Robinson and Stokes remarked 5 , bringing a lamp up to an apparatus in which the object was to measure diffusion in an undisturbed solution in which all bulk flow had (they hoped) been eliminated over many days immediately introduces convection currents that would nullify their efforts.

Joseph and Preziosi criticized' Fourier's theory of heat propagation in solids because they believed he had overlooked or neglected a factor for the movement of heat by radiation. Fourier had not in fact overlooked radiant heat ${ }^{+}$, but considered it a minor phenomenon in the circumstances and kinds of solids he was investigating. Article 433 of his theory states: "luminous heat penetrates solids and liquids and is gradually absorbed by them after traversing a certain distance When this distance has finite value, the differential equations take a different form, which could offer no useful application unless based on experimental knowledge which we have not yet acquired."

That light passes through glass (solid) and emerges as light and radiant heat seems common-sense confirmation of the concept that wave energy moves through and heats solid matter. Moreover, Fourier said that the coefficients used in his theory as constants were in fact constant only within narrow ranges. Having so fastidiously constrained his theory, Fourier would probably agree that, used outside those limits, it might be "the crudest approximation to the truth".

If, therefore, Fourier's mathematics are still considered inadequate in describing heat movement in metal bars, then Fick's transformation of it for material movement in liquid must also be suspect. We are therefore surprised that no one has drawn attention to the possibility that the diffusion equation may be an even bigger can of worms.

Biologists lay great emphasis on diffusion as the means whereby molecules move from one part of a cell or tissue to another. But diffusion should surely be seen as occurring in a field of force. It is too often invoked as a satisfactory explanation for molecular movement within cells and organisms, without experimental evidence to support it.

We wonder whether too much credence is placed on diffusion by biologists, whether or not diffusion theory is flawed. Diffusion in its simple (unassisted) form often has little relevance or place in meta-

\section{$\mathrm{N}_{2} \mathrm{O}$ production in the ocean}

SIR-Recent measurements of the ${ }^{15} \mathrm{~N}:{ }^{14} \mathrm{~N}$ ratio $\left(\delta^{15} \mathrm{~N}\right)$ of dissolved nitrous oxide $\left(\mathrm{N}_{2} \mathrm{O}\right)$ in sea water have revived the controversy concerning the mechanisms of $\mathrm{N}_{2} \mathrm{O}$ production in the ocean. The observed high $\delta^{15} \mathrm{~N}$ of $\mathrm{N}_{2} \mathrm{O}$ has been interpreted differently by Yoshida et al.' and by Kim and Craig ${ }^{2}$ to support its production through denitrification and nitrification, respectively. I propose an alternate mechanism involving the possible coupling of the two processes through nitric oxide (NO) at low oxygen concentrations which may as well explain the isotope data.

The issue of whether denitrification could be a significant mechanism of $\mathrm{N}_{2} \mathrm{O}$ production has been addressed ${ }^{2.3}$. Although the lack of information on the isotope composition of ammonia in the oxygenminimum zone represents a serious shortcoming in the existing data sets, it seems fairly obvious that sizeable $\mathrm{N}_{2} \mathrm{O}$ production should occur through an intermediate species which is enriched in ${ }^{15} \mathrm{~N}$ (and ${ }^{18} \mathrm{O}$ ). It is probable that hydroxylamine ( $\left.\mathrm{NH}_{2} \mathrm{OH}\right)$, produced through nitrification, is one such compound, as suggested by $\mathrm{Kim}$ and $\mathrm{Craig}^{2}$. However, instead of the direct production of $\mathrm{N}_{2} \mathrm{O}$ through the oxidation of $\mathrm{NH}, \mathrm{OH}$, there could be another intermediate, NO, which could be reduced to $\mathrm{N}_{2} \mathrm{O}$ within the microenvironments. There are several points that support this pathway $\left(\mathrm{NH}_{4}^{+} \rightarrow \mathrm{NH}_{2} \mathrm{OH}\right.$ $\rightarrow \mathrm{NO} \rightarrow \mathrm{N}_{2} \mathrm{O}$ ). (1) $\mathrm{NO}$ is believed to be produced during nitrification at low oxygen concentrations. Ward and Zafiriou bolic processes and offers very limited scope for their sensitive regulation. If Fourier can be mistakenly criticized for ignoring radiant heat, Fick can be called to task not only for his extrapolations, but for ignoring convection. At the molecular level, continuing faith in diffusion may be a legacy of traditional biochemistry, in which enzymatic reactions were seen as events occurring in homogenates or solutions where the law of mass action could be simply applicd.

273 Kingsbury Road, Erdington. Birmingham B24 8RD, UK

P. C. Malone

Department of Pathology,

University Medical Buildings,

Foresterhill, Aberdeen AB9 2ZD, UK

1. Naddox, J. Nature 338, 373 (1989).

2. Joseph, D. D. \& Preziosi, L. Rev. Mod. Phys. 61, 41-73 (1989).

3. Fourier, J. B. Theorie Analytique de la Chateur (Oeuvres Paris, 1822)

4. Fick, A. Ann Phys, Lpz. 170, 59-86 (1855)

5. Robinson, R. A. \& Stokes, R. H. Electrolyte Solutions (Butterworths, London, 1965)

estimated $^{+}$that the vertically integrated NO flux could be as much as $13 \%$ of the nitrification flux in the eastern tropical North Pacific. (2) The maxima in NO concentration and turnover rate are located at about the same level as those of $\mathrm{N}_{2} \mathrm{O}$, near the boundaries of the oxygen-deficient layer ${ }^{4}$. This implies a close relationship between $\mathrm{NO}$ and $\mathrm{N}_{2} \mathrm{O}$. (3) $\mathrm{NO}$ produced during nitrification is significantly enriched (by up to $20 \%$ o relative to $\mathrm{NH}_{4}^{+}$) in ${ }^{15} \mathrm{~N}$, whereas $\mathrm{N}_{2} \mathrm{O}$ produced during this process is severely depleted". (4) The mechanism favoured by Kim and Craig cannot easily account for a large increase in the extent of $\mathrm{N}_{2} \mathrm{O}$ production at low oxygen concentrations. This requires a reduction step: either "nitrifier denitrification' $\left(\mathrm{NO}_{2}^{-} \rightarrow \mathrm{N}_{2} \mathrm{O}\right)$ or the mechanism proposed here. The fact that the former process leads to large ${ }^{15} \mathrm{~N}$ depletion suggests that it may not be dominant.

The nitrification-denitrification couple can also account for the low yields of $\mathrm{N}_{2} \mathrm{O}$ during the incubation experiments of Yoshida et al. ${ }^{1}$. This could merely reflect the scarcity of large particles within which conditions favourable for $\mathrm{NO}$ reduction could develop.

The maximum in $\delta^{15} \mathrm{~N}$ is located significantly below the oxygen minimum ${ }^{2}$. And as the maximal $\mathrm{N}_{2} \mathrm{O}$ concentrations are found within the oxygen minimum', it is clear that the mechanism(s) leading to the greater ${ }^{\text {Is }} \mathrm{N}$ enrichment in $\mathrm{N}_{2} \mathrm{O}$ in deep water may not also be mainly responsible for its production. It seems to me that there may be several mechanisms of $\mathrm{N}_{2} \mathrm{O}$ production. As refs 1 and 2 both reveal lower $\delta^{15} \mathrm{~N}$ in $\mathrm{N}_{2} \mathrm{O}$ in the upper layers compared with the deep sea, the pathway $\mathrm{NH}_{+}^{+} \rightarrow \mathrm{NO}_{2}^{-} \rightarrow \mathrm{N}_{2} \mathrm{O}$ (ref. 5) might con- 